\title{
EXTRACTION OF DISSOLVED INORGANIC CARBON (DIC) FROM SEAWATER SAMPLES AT CEDAD: RESULTS OF AN INTERCOMPARISON EXERCISE ON SAMPLES FROM ADRIATIC SEA SHALLOW WATER
}

\author{
$\mathrm{M} \mathrm{Macchia}^{1} \bullet \mathrm{M} \mathrm{D}^{\prime} \mathrm{Elia}^{1} \bullet \mathrm{G}^{\text {Quarta }^{1}} \bullet \mathrm{V} \mathrm{Gaballo}^{1} \bullet \mathrm{E} \mathrm{Braione}^{1} \bullet \mathrm{L} \mathrm{Maruccio}^{1} \bullet \mathrm{L}^{\text {L Calcagnile }}$ M $^{1,2}$ \\ $\mathrm{G} \mathrm{Ciceri}^{3} \cdot \mathrm{V}$ Martinotti $^{3} \cdot \mathrm{L} \mathrm{Wacker}^{4}$
}

\begin{abstract}
A dedicated sample processing line for the extraction of dissolved inorganic carbon (DIC) from seawater and groundwater for accelerator mass spectrometry (AMS) radiocarbon analysis has been developed at CEDAD, the Center for Dating and Diagnostic of the University of Salento, Lecce, Italy. The features of the new system are presented together with tests carried out to determine its functionality and background levels. The first results obtained at CEDAD for analyzing seawater samples taken from the Northern Adriatic compare well with results obtained for the same samples analyzed at ETH Zurich.
\end{abstract}

\section{INTRODUCTION}

Measurements of the radiocarbon concentration of inorganic carbon dissolved in seawater play a major role in several aspects related to global carbon cycle and ocean water mass circulation (Povinec et al. 2004; McDuffee and Druffel 2007). Since most of the carbon dioxide is dissolved in ocean water, the ocean carbonate system governs the carbon cycle largely by determining the pressure of $\mathrm{CO}_{2}$ in the atmosphere (Emerson and Hedges 2008). Another important field in which understanding the carbonate system is of paramount importance is related to carbon capture and sequestration (CCS) studies (Feely et al. 2004). In fact, the possibility to capture carbon dioxide from industrial sources and to store it deep under the sea surface is being evaluated (IPCC 2005) and pilot projects are being planned in different countries.

In order to improve the experimental capabilities of the accelerator mass spectrometry (AMS) facility at the University of Salento (CEDAD: Centre for Dating and Diagnostics), a new preparation line dedicated to the extraction of dissolved inorganic carbon (DIC) from seawater and groundwater has been installed. This article presents the general features of the new extraction line together with the results of performance tests carried out in order to assess the background of the line and achievable recovery yields. The reproducibility of the measurements was also evaluated by comparing the results obtained at CEDAD on seawater sampled by RSE ((Ricerca sul Sistema Energetico, Sustainable Development and Energy Sources, Milan, Italy) in the Northern Adriatic with those obtained at the AMS facility at the Swiss Federal Institute of Technology, ETH, Zurich, Switzerland.

\section{METHODS}

\section{System Description}

DIC is extracted from water samples as gaseous $\mathrm{CO}_{2}$ using a vacuum extraction line based on a modified approach of McNichol et al. (1994). The line consists of a Pyrex ${ }^{\mathrm{TM}}$ manifold to which a vacuum gauge (operating range: $5 \times 10^{-4}$ to $1000 \mathrm{mbar}$ ) is connected in order to monitor the pressure during the different phases of the extraction process. As shown in Figure 1, the manifold consists of

\footnotetext{
${ }^{1}$ CEDAD-Department of Engineering for Innovation, University of Salento, via per Monteroni, 73100 Lecce, Italy.

${ }^{2}$ Corresponding author. Email: Lucio.calcagnile@unile.it.

${ }^{3}$ Ricerca sul Sistema Energetico-RSE spa, Sustainable Development and Energy Sources, Via R. Rubattino, 54, 20134, Milan, Italy.

${ }^{4}$ Laboratory for Ion Beam Physics, ETH Zurich, Honggerberg 8093, Zurich, Switzerland.
} 


\section{Macchia et al.}

i) a system for accommodating the aqueous sample fitted with a graduated cylinder for injecting water and orthophosphoric acid; ii) an $-80^{\circ} \mathrm{C}$ water trap; iii) a liquid nitrogen trap for carbon dioxide freezing; and iv) up to 3 vessels used to trap and transport the extracted $\mathrm{CO}_{2}$.

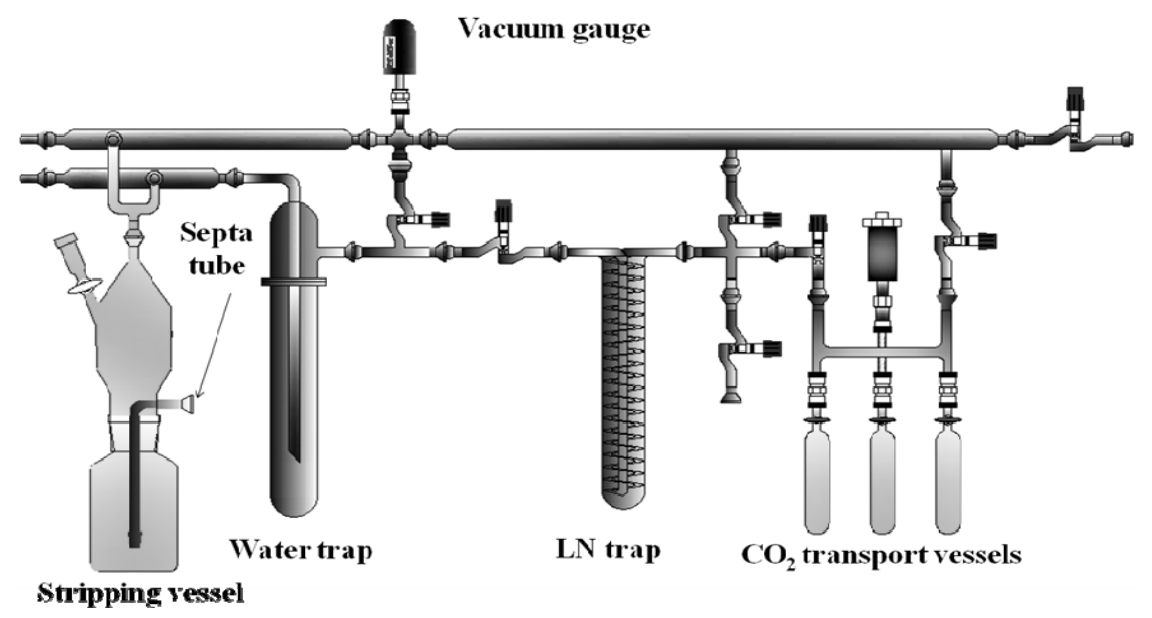

Figure 1 General scheme of the line for DIC extraction from water samples installed at CEDAD

The seawater container ("stripping vessel" in Figure 1) is attached to the vacuum line where a pressure of $\sim 10^{-3}$ mbar is obtained by an oil-free rotary pump. After evacuation, $60 \mathrm{~mL}$ of sample are injected and DIC is extracted as $\mathrm{CO}_{2}$ by adding phosphoric acid $\left(2 \mathrm{~mL}\right.$ of $\left.85 \% \mathrm{H}_{3} \mathrm{PO}_{4}\right)$ with a syringe through a septa-sealed tube. The $\mathrm{CO}_{2}$ released is then frozen into the liquid nitrogen trap, after removal of water vapor by the $-80^{\circ} \mathrm{C}$ trap. No carrier gas is used during the process and the complete extraction procedure is carried out under static vacuum conditions.

After the extraction process, the $\mathrm{CO}_{2}$ produced is cryogenically transferred to an ampoule with a calibrated volume where its amount is determined by measuring the corresponding pressure with a transducer. The extracted gas is then transferred to the graphitization line to be converted to graphite at $600{ }^{\circ} \mathrm{C}$ by using hydrogen as the reducing agent and iron powder as catalyst (D'Elia et al. 2004). The graphite is then pressed into the aluminum target holders of the AMS system ion source for measurement of the ${ }^{14} \mathrm{C}$ concentration (Calcagnile et al. 2004, 2005).

\section{Background Samples}

In order to test the extraction yield and the blank level of the new line, several test samples were prepared by dissolving with acid IAEA-C1 standards (Carrara marble) with a certified ${ }^{14} \mathrm{C}$ content of $0 \mathrm{pMC}$ in deionized water. Different carbonate samples with masses ranging from 0.2 to $2.2 \mathrm{mg}$ were prepared in order to measure the dependence of the background on the sample mass. The extraction yield was then calculated as the ratio between the equivalent mass of carbon added as $\mathrm{CaCO}_{3}$ and the mass of carbon contained in the extracted $\mathrm{CO}_{2}$, measured in the calibrated volume.

\section{Seawater Samples}

The first measurements on seawater were carried out on 14 samples taken in the Northern Adriatic Sea at depths ranging from 14 to $30 \mathrm{~m}$ (Figure 2). Table 1 lists the samples together with the sampling sites and depth. Samples with the CEDAD laboratory code starting with 5 were samples from October 2010 and those starting with 8, from January/February 2011. Each sample consisted of 
$250 \mathrm{~mL}$ (from which $60 \mathrm{~mL}$ were used for AMS analysis at CEDAD) of seawater sampled with a benthic chamber and Niskin bottles, poisoned on-site with $\mathrm{HgCl}_{2}$ to stop biological activity, and stored at $4{ }^{\circ} \mathrm{C}$ until processing. All samples showed a DIC concentration of $\sim 2500 \mu \mathrm{mol} / \mathrm{kg}$ as determined by a flow-injection analyzer conductometric coupled system developed by RSE (Martinotti et al. 2012).



Figure 2 Sampling sites in the Northern Adriatic Sea. The sampling depths were as follows: 2E: $28 \mathrm{~m}$; $3 \mathrm{~A}: 14 \mathrm{~m}$; $5 \mathrm{C} 1$ : $31 \mathrm{~m} ; 8 \mathrm{~A}: 30 \mathrm{~m}$; 18C: $20 \mathrm{~m}$.

Table 1 List of the analyzed seawater samples, of CEDAD and ETH laboratory codes, sampling sites and measured radiocarbon concentrations.

\begin{tabular}{lllllrl}
\hline $\begin{array}{l}\text { CEDAD } \\
\text { ID }\end{array}$ & $\begin{array}{l}\text { Sampling } \\
\text { site }^{\mathrm{a}}\end{array}$ & $\begin{array}{l}\text { ETH- } \\
\text { ID }\end{array}$ & $\begin{array}{l}\text { CEDAD value } \\
(\mathrm{pMC})\end{array}$ & $\begin{array}{l}\text { ETH value } \\
(\mathrm{pMC})\end{array}$ & \multicolumn{1}{c}{$\Delta$} & $t$ \\
\hline LTL5802A & 2E & 45372 & $103.97 \pm 0.59$ & $104.25 \pm 0.51$ & -0.28 & 0.36 \\
LTL5805A & 3A & 45374 & $102.65 \pm 0.50$ & $102.47 \pm 0.49$ & 0.18 & 0.26 \\
LTL5807A & 5C1 & 45375 & $103.86 \pm 0.50$ & $104.13 \pm 0.50$ & -0.27 & 0.38 \\
LTL5808A & $8 \mathrm{~A}$ & 45376 & $104.58 \pm 0.50$ & $104.79 \pm 0.51$ & -0.21 & 0.29 \\
LTL5809A & 8A & 45377 & $104.69 \pm 0.87$ & $103.69 \pm 0.52$ & 1.00 & 0.99 \\
LTL5810A & 18C & 45378 & $103.30 \pm 0.50$ & $103.35 \pm 0.51$ & -0.05 & 0.07 \\
LTL8657A & 2E & - & $104.35 \pm 0.53$ & - & - & - \\
LTL8660 A & 5C1 & 45382 & $105.07 \pm 0.48$ & $104.31 \pm 0.49$ & 0.76 & 1.11 \\
LTL8661A & $8 \mathrm{~A}$ & 45384 & $104.19 \pm 0.50$ & $103.71 \pm 0.48$ & 0.48 & 0.69 \\
LTL8662A & 18C & 45387 & $102.18 \pm 0.50$ & $101.65 \pm 0.47$ & 0.53 & 0.77 \\
LTL8663A & 3A & 45380 & $102.48 \pm 0.49$ & $101.59 \pm 0.50$ & 0.89 & 1.27 \\
LTL8664A & 5C1 & 45381 & $103.58 \pm 0.50$ & $102.50 \pm 0.52$ & 1.08 & 1.50 \\
LTL8665A & 8A & 45383 & $105.55 \pm 1.2$ & $104.62 \pm 0.50$ & 0.93 & 0.72 \\
LTL8666A & 18C & 45386 & $104.55 \pm 0.48$ & $103.91 \pm 0.49$ & 0.64 & 0.93 \\
\hline
\end{tabular}

${ }^{\mathrm{a}}$ See Figure 2. 


\section{Macchia et al.}

Thirteen samples were also sent to ETH Zurich for an independent analysis of the ${ }^{14} \mathrm{C}$ concentration in the DIC. At ETH, DIC was extracted from $12 \mathrm{~mL}$ of seawater (acidified with $1 \mathrm{~mL}$ of $85 \%$ $\mathrm{H}_{3} \mathrm{PO}_{4}$ ) in 40-mL septa-sealed vials (Molnár et al. 2013). Between 200 and $300 \mu \mathrm{g}$ carbon were extracted as $\mathrm{CO}_{2}$ and transported in a helium flow to the automated graphitization system (AGE), where it was converted to graphite (Němec et al. 2010; Wacker et al. 2013). The samples were measured on the MICADAS at ETH (Synal et al. 2007).

\section{RESULTS AND DISCUSSION}

Overall, an extraction yield above $90 \%$ was obtained as the ratio between the equivalent mass of carbon added as $\mathrm{CaCO}_{3}$ and the mass of carbon contained in the extracted $\mathrm{CO}_{2}$. Figure 3 shows the ${ }^{14} \mathrm{C}$ concentrations measured for the blank samples obtained on IAEA-C1 standards as a function of the added mass of carbonate expressed as the equivalent mass of carbon. The results clearly indicate a dependence of the background level on the sample mass, as expected (Tisnérat-Laborde et al. 2001). Nevertheless, for standard samples, i.e. yielding more than $\sim 1 \mathrm{mg} \mathrm{C}$, an overall background level of $0.3 \mathrm{pMC}$, corresponding to $\sim 47 \mathrm{ka}$ in the ${ }^{14} \mathrm{C}$ timescale, is measured. This value is comparable with the sample processing background measured on organic samples undergoing the combustion process, which is estimated to be $\sim 0.28 \mathrm{pMC}$ (D'Elia et al. 2004).



Figure 3 Radiocarbon concentration measured on "blank" samples obtained by dissolving IAEA-C1 Carrara marble in deionized water as a function of the added mass of carbonate.

The results obtained in the analysis of the North Adriatic seawater samples at CEDAD and ETH are listed in Table 1 and shown in Figure 4 with the corresponding $1 \sigma$ error bars. The difference between the values measured in the 2 laboratories is also given ( $\Delta$ in Table 1$)$ together with the discrepancy ( $t$ in Table 1) calculated as $\Delta$ divided by the square root of the sum of the squares of the corresponding uncertainties. It should be noted that the calculated values of the $t$ term are all smaller than 1.96, which indicates agreement between the measurements performed in the 2 laboratories at the $95 \%$ level. 


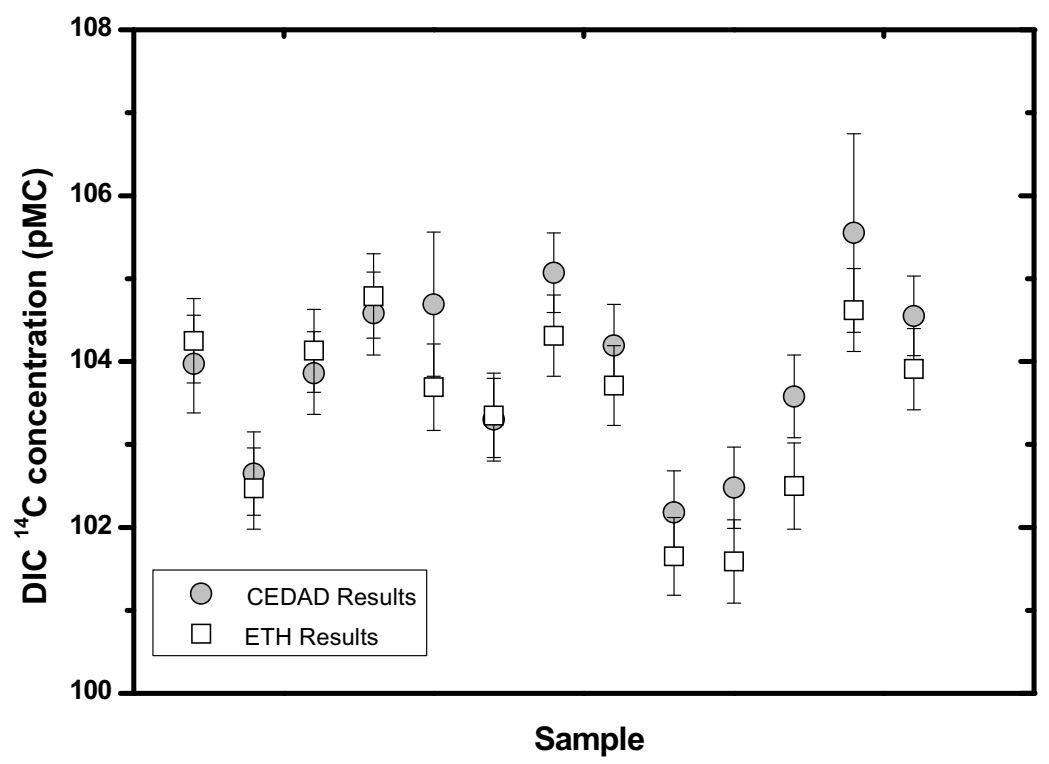

Figure 4 Comparison between the values measured on seawater samples taken in the Northern Adriatic Sea at CEDAD and ETH.

\section{CONCLUSIONS}

A new line installed at CEDAD for the extraction of DIC from water samples has been presented. The general features of the line have been described together with the results of blank tests and of an intercomparison exercise on shallow seawater sampled in the Northern Adriatic Sea. Blank tests were carried out by analyzing samples obtained by dissolving ${ }^{14} \mathrm{C}$-free IAEA C-1 standards into deionized water and showed a background level of $\sim 0.3 \mathrm{pMC}$ for samples with a mass of $\sim 1 \mathrm{mg} \mathrm{C}$. For smaller samples, an increase of the measured background was highlighted as the sample mass decreases. The results of the intercomparison exercise carried out with the AMS group at ETH Zurich are in very good agreement and show good reproducibility of the obtained results.

\section{ACKNOWLEDGMENTS}

The installation of the sample processing line for DIC extraction from seawater samples was funded by the Italian Ministry for Research and Education in the framework of the "Blu-Archeosys" project. This work has been financed by the Research Fund for the Italian Electrical System under the Contract Agreement between RSE S.p.A. and the Ministry of Economic Development - General Directorate for Nuclear Energy, Renewable Energy and Energy Efficiency in compliance with the Decree of March 8, 2006.

\section{REFERENCES}

Calcagnile L, Quarta G, D’Elia M, Rizzo A, Gottdang A, Klein M, Mous DJW. 2004. A new accelerator mass spectrometry facility in Lecce, Italy. Nuclear Instruments and Methods in Physics Research B 223-224: $16-20$.

Calcagnile L, Quarta G, D'Elia M. 2005. High-resolution accelerator-based mass spectrometry: precision, accu- racy and background. Applied Radiation and Isotopes 62(4):623-9.

D’Elia M, Calcagnile L, Quarta G, Rizzo A, Sanapo C, Laudisa M, Toma U, Rizzo A. 2004. Sample preparation and blank values at the AMS radiocarbon facility of the University of Lecce. Nuclear Instruments and Methods in Physics Research B 223-224:278-83. 


\section{Macchia et al.}

Emerson S, Hedges J. 2008. Chemical Oceanography and the Marine Carbon Cycle. Cambridge: Cambridge University Press.

Feely RA, Sabine CL, Lee K, Berelson W, Kleypas J, Fabry VJ, Millero F J. 2004. Impact of anthropogenic $\mathrm{CO}_{2}$ on the $\mathrm{CaCO}_{3}$ system in the ocean. Science 305(5682):362-6.

Intergovernmental Panel on Climate Change (IPCC). 2005. Metz B, Davidson O, de Coninck HC, Loos M, Meyer LA, editors. IPCC Special Report on Carbon Dioxide Capture and Storage. Prepared by Working Group III of the Intergovernmental Panel on Climate Change. Cambridge: Cambridge University Press. $442 \mathrm{p}$.

Martinotti V, Balordi M, Ciceri G. 2012. A flow injection analyser conductometric coupled system for the field analysis of free dissolved $\mathrm{CO}_{2}$ and total dissolved inorganic carbon in natural waters. Analytical and Bioanalytical Chemistry 403(4):1083-93.

McDuffee K, Druffel ERM. 2007. Daily variability of dissolved inorganic radiocarbon in Sargasso Sea surface water. Marine Chemistry 106(3-4):510-5.

McNichol AP, Jones GA, Hutton DL, Gagnon AR.1994. The rapid preparation of seawater $\Sigma \mathrm{CO}_{2}$ for radiocarbon analysis at the National Ocean Sciences AMS fa- cility. Radiocarbon 36(2):237-46.

Molnár M, Hajdas I, Janovics R, Rinyu L, Synal H-A, Veres M, Wacker L. 2013. C-14 analysis of groundwater down to the millilitre level. Nuclear Instruments and Methods in Physics Research B 294:573-6.

Němec N, Wacker L, Gäggeler H. 2010. Optimization of the graphitization process at AGE-1. Radiocarbon 52(3):1380-93.

Povinec PP, Aramaki T, Burr GS, Jull AJT, Kwong LLW, Togawa O. 2004. Radiocarbon in the water column of the southwestern North Pacific Ocean 24 years after GEOSECS. Radiocarbon 46(2):583-94.

Synal H-A, Stocker M, Suter M. 2007. MICADAS: a new compact radiocarbon AMS system. Nuclear Instruments and Methods in Physics Research B 259(1): 7-13.

Tisnérat-Laborde N, Poupeau JJ, Tannau JF, Paterne M. 2001. Development of a semi-automated system for routine preparation of carbonate samples. Radiocarbon 43(2A):299-304.

Wacker L, Fülöp RH, Hajdas I, Molnár M, Rethemeyer J. 2013. A novel approach to process carbonate samples for radiocarbon measurement with helium gas carrier. Nuclear Instruments and Methods in Physics Research B 294:214-7. 